\title{
OPTIMIZATION OF POLYURETHANE FOAM CUBE IN ENHANCING THE ATTACHMENT OF MICROALGAE BIOMASS
}

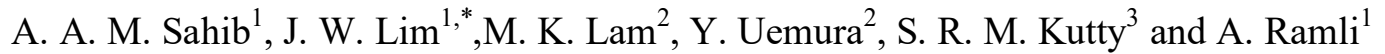 \\ ${ }^{1}$ Fundamental and Applied Science Department, UniversitiTeknologi PETRONAS, 32610 \\ Seri Iskandar, Perak, Malaysia \\ ${ }^{2}$ Chemical Engineering Department, UniversitiTeknologi PETRONAS, 32610 Seri Iskandar, \\ Perak, Malaysia \\ ${ }^{3}$ Civil and Environmental Engineering Department, UniversitiTeknologi PETRONAS, 32610 \\ Seri Iskandar, Perak, Malaysia
}

Published online: 10 November 2017

\begin{abstract}
Attachment of microalgae biomass to polyurethane foam material is believed could reduce the cost and time needed for harvesting process in making it reliable to be used in industry for biodiesel production. This paper aim to optimize the usage of polyurethane for higher attachment of microalgae biomass yield in term of it sizes and packing volume. The investigation revealed that $1.0 \mathrm{~cm}^{3}$ polyurethane foam yield highest attached biomass $(0.812 \mathrm{~g})$ and it has best performance compared to $0.125 \mathrm{~cm}^{3}, 8 \mathrm{~cm}^{3}$ and $27 \mathrm{~cm}^{3}$ with attached biomass yield $0.666 \mathrm{~g}, 0.546 \mathrm{~g}$, and $0.368 \mathrm{~g}$ respectively. For packing volume, $6 \%$ is the best since has highest attached microalgae biomass with yield $0.753 \mathrm{~g}$, compared with $2 \%, 4 \%, 8 \%$ and $10 \%$ with yield $0.426 \mathrm{~g}, 0.577 \mathrm{~g}, 0.687 \mathrm{~g}$ and $0.644 \mathrm{~g}$ attached biomass respectively.
\end{abstract}

Keywords: microalgae; chlorella vulgaris; polyurethane; attached biomass.

Author Correspondence, e-mail: junwei.lim@utp.edu.my

doi: http://dx.doi.org/10.4314/jfas.v9i6s.49 


\section{INTRODUCTION}

Microalgae are efficient in converting solar energy into cell biomass riching with triglycerides that can be exploited for biodiesel production via transesterification process [1]. It has high growth rate, lower demand for water than commercial crops, high efficiency in $\mathrm{CO}_{2}$ mitigation and small areas requirement for cultivation [2]. In [3] confirmed that microalgae had much higher growth rates and productivity as compared with conventional forestry, agricultural crops and other aquatic plants, besides requiring lesser land area than other biodiesel feedstock of agricultural origin i.e., up to 132 times lower than soybean crops for an equivalent of $30 \mathrm{wt} \%$ of oil content. Accordingly, of all the potential feedstock for biofuels, microalgae are perceived to be the only possible feedstock that can significantly replace petroleum-based fuels [4].

However, harvesting is the biggest challenge in producing biodiesel from microalgae. Although intensive researches on the microalgae-derived biofuels had been made, the commercial production system is still unable to achieve economic viability due to the expensive harvesting method [5]. In this case, extensive time and energy are required to handle large feedstock volumes during the harvesting stage, leading to the production of low value products such as biodiesel [6]. So alternative methods must be investigated to overcome this problem in making the biodiesel a much reliable and economical source to be used broadly. Cultivation of attached growth microalgae to a solid carrier has been attracting serious attention as it has a potential to reduce the energy and cost [7].

In this present research, polyurethane foam material served as fluidized bed in order to attach the microalgae growth in bioreactor. Polyurethane is used as it has high porosity and is a suitable medium for biomass immobilization [8] and has good mechanical strength and low cost [9-10]. The aim of this research is first to determine the best polyurethane foam cube size and second to determine the suitable packing volume of the polyurethane foam cube so that the attachment of microalgae can be optimized.

\section{EXPERIMENTAL}

\subsection{Microalgae Species and Culture Condition}

The Chlorella vulgaris used as the microalgae model was obtained from the culture collection 
from the Centre for Biofuel and Biochemical Research (CBBR) of UniversitiTechnologi PETRONAS (UTP). The microalgae was grown in Bold's Basal Medium (BBM), prepared by mixing: (1) $10 \mathrm{~mL}$ per liter of the following chemicals: $\mathrm{NaNO}_{3}(25 \mathrm{~g} / \mathrm{L}), \mathrm{CaCl}_{2} \cdot 2 \mathrm{H}_{2} \mathrm{O}(2.5$ $\mathrm{g} / \mathrm{L}), \mathrm{MgSO}_{4} .7 \mathrm{H}_{2} \mathrm{O}(7.5 \mathrm{~g} / \mathrm{L}), \mathrm{K}_{2} \mathrm{HPO}_{4}(7.5 \mathrm{~g} / \mathrm{L}), \mathrm{KH}_{2} \mathrm{PO}_{4}(17.5 \mathrm{~g} / \mathrm{L}), \mathrm{NaCl}(2.5 \mathrm{~g} / \mathrm{L})$ and (2) 1 $\mathrm{mL}$ per liter of the following chemicals: EDTA anhydrous $(50 \mathrm{~g} / \mathrm{L}), \mathrm{KOH}(31 \mathrm{~g} / \mathrm{L})$, $\mathrm{FeSO}_{4} .7 \mathrm{H}_{2} \mathrm{O}(4.98 \mathrm{~g} / \mathrm{L}), \mathrm{H}_{2} \mathrm{SO}_{4}(1 \mathrm{~mL}), \mathrm{H}_{3} \mathrm{BO}_{3}(11.4 \mathrm{~g} / \mathrm{L}), \mathrm{ZnSO}_{4} .7 \mathrm{H}_{2} \mathrm{O}(8.82 \mathrm{~g} / \mathrm{L})$, $\mathrm{MnCl}_{2} .4 \mathrm{H}_{2} \mathrm{O}(1.44), \mathrm{MoO}_{3}(0.71 \mathrm{~g} / \mathrm{L}), \mathrm{CuSO}_{4} .5 \mathrm{H}_{2} \mathrm{O}(1.57 \mathrm{~g} / \mathrm{L}), \mathrm{Co}\left(\mathrm{NO}_{3}\right)_{2} .6 \mathrm{H}_{2} \mathrm{O}(0.49 \mathrm{~g} / \mathrm{L})$. The with initial $\mathrm{pH}$ of the culture medium being adjusted to $\mathrm{pH} 5$ and used as the seed for later experiment upon reaching stationary stage. The culture was aerated using compressed air and illuminated with cool-white fluorescent light (Philip TL-D 36W/865, light intensity of $60-70 \mu \mathrm{mol} / \mathrm{m}^{2} \mathrm{~s}$ ) with surrounding temperature fluctuating between $25^{\circ} \mathrm{C}$ and $28^{\circ} \mathrm{C}$ continuously for 24 hours.

\subsection{Cultivation Condition of Microalgae with Different Polyurethane Foam Size}

Five bioreactors with working volume of $1 \mathrm{~L}$ each $(100 \mathrm{~mL}$ seed culture and $900 \mathrm{~mL}$ liquid medium) were setup separately in 1 L Erlenmeyer flasks. Each flask was individually packed with $2.4 \%(\mathrm{v} / \mathrm{v})$ of polyurethane foam cubes with the respective size of $0.5 \mathrm{~cm} \times 0.5 \mathrm{~cm} \times 0.5$ $\mathrm{cm}, 1 \mathrm{~cm} \times 1 \mathrm{~cm} \times 1 \mathrm{~cm}, 2 \mathrm{~cm} \times 2 \mathrm{~cm} \times 2 \mathrm{~cm}$ and $3 \mathrm{~cm} \times 3 \mathrm{~cm} \times 3 \mathrm{~cm}$ with the respective cube volume of $0.125 \mathrm{~cm}^{3}, 1 \mathrm{~cm}^{3}, 8 \mathrm{~cm}^{3}$ and $27 \mathrm{~cm}^{3}$. The optical densities for suspended microalgae were taken daily using UV-VIS spectrometer.

\subsection{Cultivation Condition of Microalgae with Different Polyurethane Foam Packing Volume}

Five bioreactors with working volume of $1 \mathrm{~L}$ each $(100 \mathrm{~mL}$ seed culture and $900 \mathrm{~mL}$ liquid medium) were setup separately in 1 L Erlenmeyer flasks. Each flask was individually packed with $1 \mathrm{~cm}^{3}$ polyurethane foam material with packing volume of $2 \%, 4 \%, 6 \%, 8 \%$ and $10 \%$. The optical densities for suspended microalgae were taken daily using UV-VIS spectrometer.

\subsection{Determination of Microalgae Biomass Yield}

For suspended microalgae biomass, the correlation between optical density and the biomass was determined. The optical density was measured using UV-VIS spectrophotometer (Shimadzu, Model: 2600) at $680 \mathrm{~nm}$. Then, $10 \mathrm{~mL}$ of sample were centrifuged at $10 \mathrm{x} 1000 \mathrm{~g}$ for 5 minutes. The supernatant was slowly decanted whereas the microalgae biomass was 
dried in an oven at $100^{\circ} \mathrm{C}$ until constant weight was achieved. The correlation is shown in Equation (1):

Dry weight $(\mathrm{g} / \mathrm{L})=0.553 \times$ OD680, $\mathrm{R} 2=0.991$

For attached microalgae, the weight of the raw polyurethane $\left(\mathrm{W}_{\mathrm{p}}\right)$ was determined gravimetrically. As the microalgae biomass attached throughout the cultivation period, on the final day of the cultivation, the polyurethane with attached microalgae were isolated separately from their reactor through skimming which were dried in an oven at $80^{\circ} \mathrm{C}$ until the weight was constant. The weight of the polyurethane foam with attached microalgae $\left(\mathrm{W}_{\mathrm{pm}}\right)$ was determined gravimetrically. The weight of the attached microalgae $\left(\mathrm{W}_{\mathrm{m}}\right)$ can be determined through the Equation (2):

$\mathrm{W}_{\mathrm{m}}=\mathrm{W}_{\mathrm{pm}}-\mathrm{W}_{\mathrm{p}}$

\section{RESULTS AND DISCUSSION}

\subsection{Determination of Optimum Size of Polyurethane Foam Cube}

Fig.1.represents suspended growth of microalgae biomass as a function of culture time in bioreactors packed with various polyurethane foam sizes. Bioreactors packed with $1.0 \mathrm{~cm}^{3}$ polyurethane foam cube, possessed the lowest suspended microalgae concentration at the end of the cultivation time. This was due to the highest biomass attachment on $1 \mathrm{~cm}^{3}$ polyurethane foam material as shown in Fig.2. Compared with the $8.0 \mathrm{~cm}^{3}$ and $27.0 \mathrm{~cm}^{3}$ polyurethane foam material, the suspended microalgae concentration were higher because of the bigger sizes of polyurethane foam cubes which inhibited the growth of the attached microalgae in the inner layers of polyurethane cubes as the supplies light intensity and carbon dioxide concentration were limited. According to [11], a number of microalgae research have shown that the growth rate of the microalgae increases with increasing light intensity. However, the trend for the attached microalgae productivities under effect of different light intensities is still unclear due to lack of controlled variables between experiments as reported studies by [12-14]. In [15] stated that the biomass increased with the increased of carbon dioxide concentration in their research on effect of carbon dioxide concentration on the growth response of Chlorella vulgaris.

For the reactor with smaller sizes of polyurethane cubes $\left(<1 \mathrm{~cm}^{3}\right)$, it possessed higher number 
of polyurethane foam cubes with lower concentrations of suspended microalgae. This may be due to the high number of polyurethane cubes that made the reactor became too congested. The continuous abrasion when these cubes suspensively moving in the bioreactors would lead to the detachment of initially attached biomass from the surface. The control bioreactor had highest suspended microalgae concentration since there was no loss of biomass due to attachment.

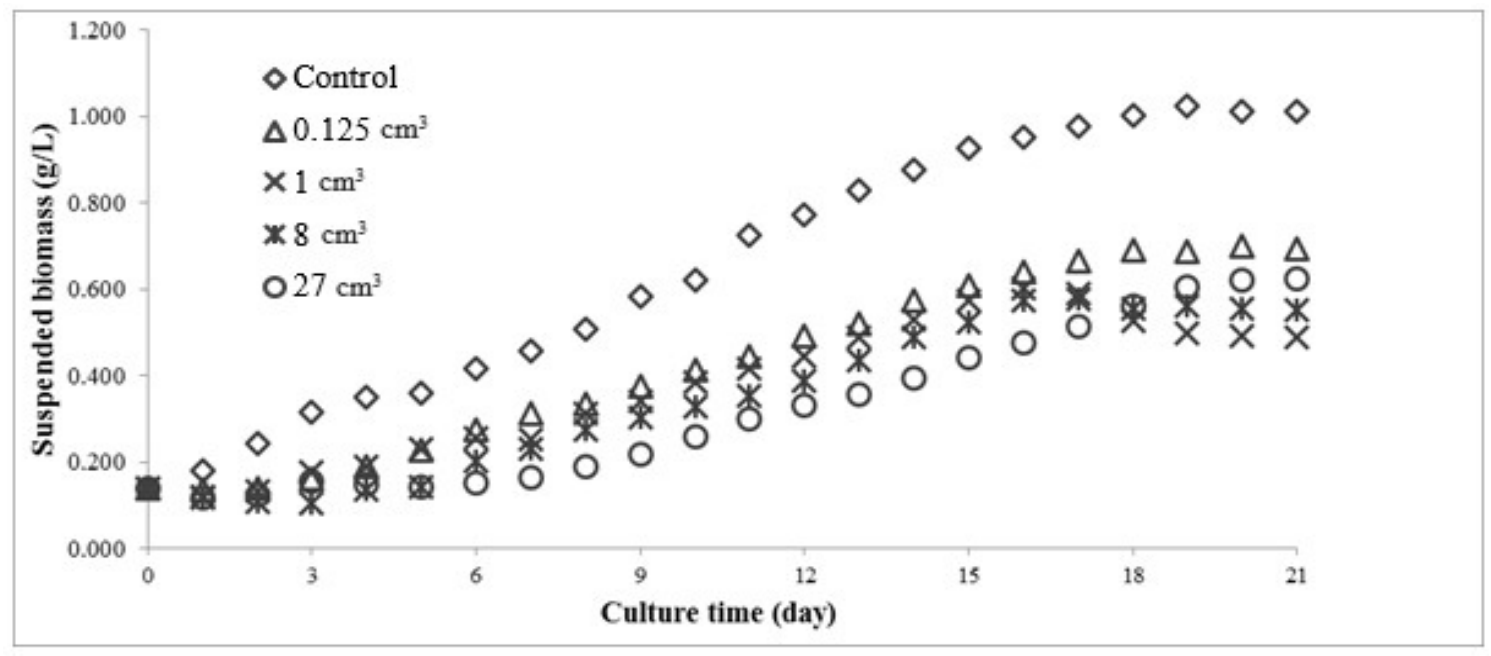

Fig.1. The growth of suspended microalgae biomass per culture time in reactor with different size of polyurethane foam material

Fig.2.shows the plot of various sizes of polyurethane foam cubes versus attached biomass weight. The graph shows that the attached microalgae biomass weight increased from the smallest polyurethane cubes to $1 \mathrm{~cm}^{3}$ of polyurethane cubes and decreased as the sizes of polyurethane were further increasing. The attached microalgae weights were higher as compared with suspended microalgae in bioreactor packed with $1 \mathrm{~cm}^{3}$ polyurethane foam cubes while for the other reactors it showed otherwise. From the total microalgae biomass weight from each bioreactor, the bioreactor with $1 \mathrm{~cm}^{3}$ polyurethane cube possessed the highest biomass weight indicating the advantage of using $1 \mathrm{~cm}^{3}$ polyurethane foam cubes as the carrier material to grow microalgae biomass. The biomass can be later and facilely harvested from bioreactor for the use of downstream processes. 


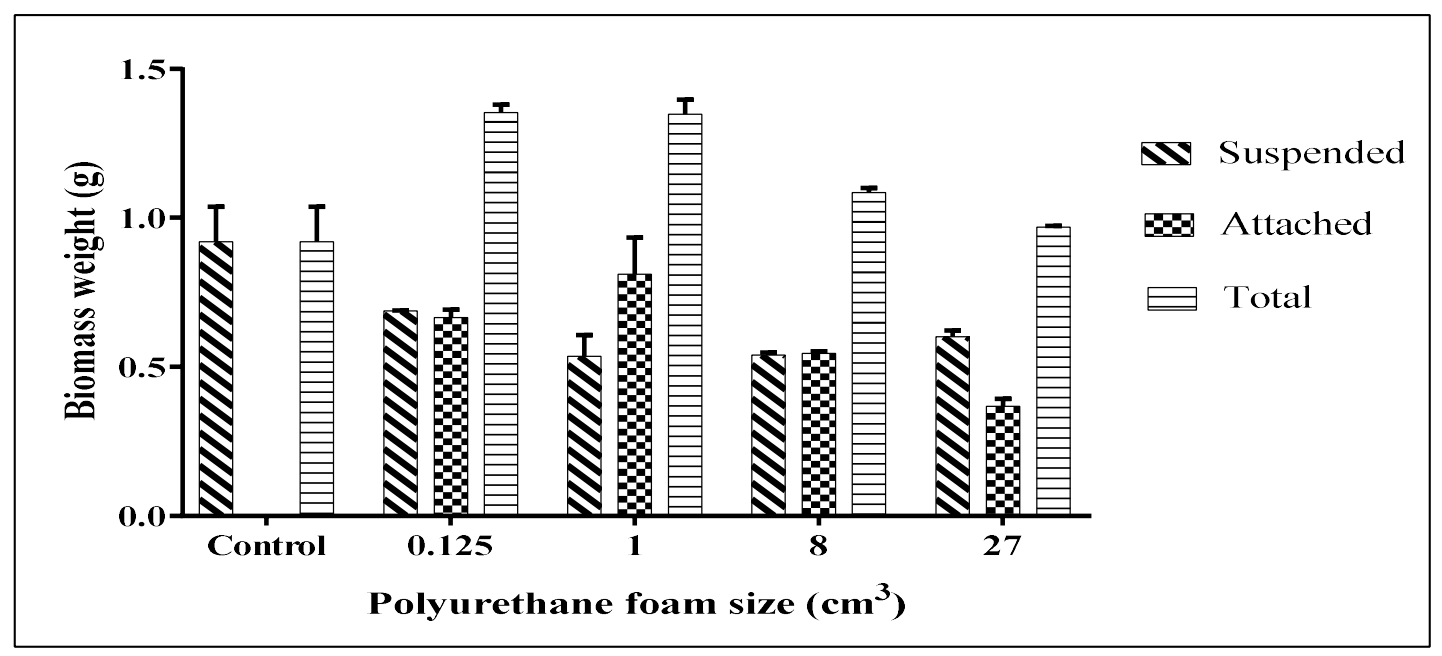

Fig.2. The suspended, attached and total microalgae biomass in bioreactor with different size of polyurethane foam material after day 21

\subsection{Determination of Optimum Packing Volume of Polyurethane Foam Cube}

From section 2.1., $1 \mathrm{~cm}^{3}$ have been proven to be the best size for the higher growth of attached microalgae biomass, the size is then used for the next experiment in which was to determine the best packing volume of the polyurethane foam material. Over $1 \mathrm{~L}$ working volume of the reactor, $2 \%, 4 \%, 6 \%, 8 \%$ and $10 \%$ packing volume of polyurethane foam material were tested. Fig.3.shows the result of the effect of different packing volume of polyurethane foam material on suspended, attached and total biomass weight. It shows that attached microalgae increased with the increase of polyurethane foam packing volume from $2 \%$ to $6 \%$. However, the number of attached biomass maintained from $6 \%$ to $10 \%$ packing volume yield of $0.64 \mathrm{~g}$ to $0.75 \mathrm{~g}$. This is due to the excess addition of packing volume which may inhibit the propagation of light and aeration in which can reduce the supply of carbon dioxide to attached microalgae and lower the agitation on the reactor. This make the microalgae prefer to grow on the suspended form rather than attach to the polyurethane foam material. According to [16], light intensity can affect the attachment of microalgae to carrier as the attachment can be weaker with limited light intensity. 


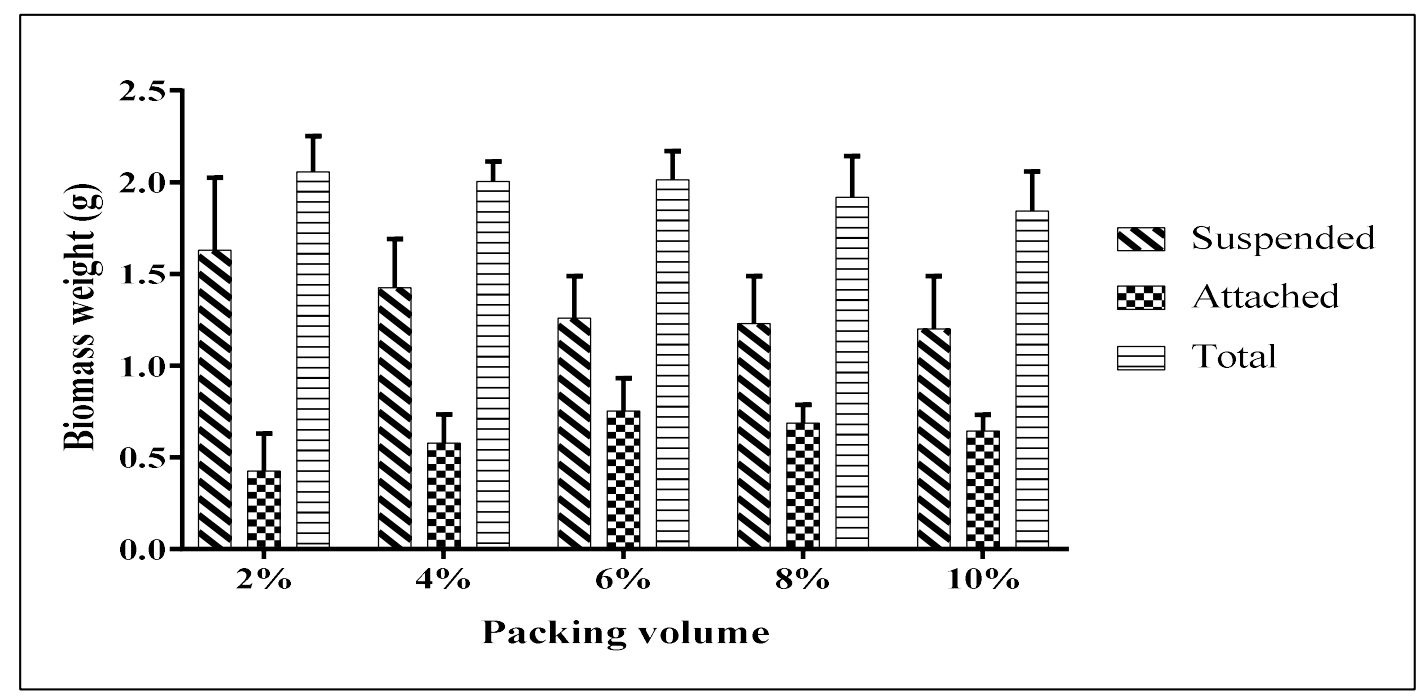

Fig.3. The suspended, attached and total microalgae biomass in bioreactor equipped with different packing volume of polyurethane foam material after day 21

\section{CONCLUSION}

This work introduce the usage of polyurethane foam material as a carrier to cultivate an attach growth microalgae in order to ease the harvesting process and reduce the cost and time of production in which make it reliable to be used in biodiesel industry. The attached microalgae showed highest number of biomass on $1 \mathrm{~cm}^{3}$ polyurethane and packing volume of $6 \%$ of total working volume of the reactor with attached biomass yield $0.812 \mathrm{~g}$ and $0.753 \mathrm{~g}$ respectively.

\section{ACKNOWLEDGEMENTS}

The authors greatfully acknowledge University Technology of PETRONAS for financially support this project via YUTP-FRG (0153AA-E48). Additional thanks to Centre for Biofuel and Biochemical Research for facilities support.

\section{REFERENCES}

[1] Borges L, Morón-Villarreyes JA, D’Oca MG, Abreu PC. Effects of flocculants on lipid extraction and fatty acid composition of the microalgae Nannochloropsisoculata and Thalassiosiraweissflogii. Biomass and Bioenergy, 2011, 35(10):4449-4454

[2] D'Alessandro EB, AntoniosiFilho NR. Concepts and studies on lipid and pigments of 
microalgae: A review. Renewable and Sustainable Energy Reviews, 2016, 58:832-841

[3] Chisti Y. Biodiesel from microalgae. Biotechnology Advances, 2007, 25(3):294-306

[4] Liu T, Wang J, Hu Q, Cheng P, Ji B, Liu J, Chen Y, Zhang W, Chen X, Chen L, Gao L. Attached cultivation technology of microalgae for efficient biomass feedstock production. Bioresource Technology, 2013, 127:216-222

[5] Show KY, Lee DJ, Mujumdar AS. Advances and challenges on algae harvesting and drying. Drying Technology, 2015, 33(4):386-394

[6] Uduman N, Qi Y, Danquah MK, Forde GM, Hoadley A. Dewatering of microalgal cultures: A major bottleneck to algae-based fuels. Journal of Renewable and Sustainable Energy, 2010, 2(1):1-15

[7] Ozkan A, Kinney K, Katz L, Berberoglu H. Reduction of water and energy requirement of algae cultivation using an algae biofilm photobioreactor. Bioresource Technology, 2012, $114: 542-548$

[8] Lim JW, Seng CE, Lim PE, Ng SL, Sujari AN. Nitrogen removal in moving bed sequencing batch reactor using polyurethane foam cubes of various sizes as carrier materials. Bioresource Technology, 2011, 102(21):9876-9883

[9] Golla PS, Reddy MP, Simms MK, Laken TJ. Three years of full-scale captorR process operation at Moundsville WWTP. Water Science and Technology, 1994, 29(10-11):175-181

[10] Chu L, Wang J. Comparison of polyurethane foam and biodegradable polymer as carriers in moving bed biofilm reactor for treating wastewater with a low $\mathrm{C} / \mathrm{N}$ ratio. Chemosphere, $2011,83(1): 63-68$

[11] Schnurr PJ, Allen DG. Factors affecting algae biofilm growth and lipid production: A review. Renewable and Sustainable Energy Reviews, 2015, 52:418-429

[12] Gross M, Henry W, Michael C, Wen Z. Development of a rotating algal biofilm growth system for attached microalgae growth with in situ biomass harvest. Bioresource Technology, 2013, 150:195-201

[13] Johnson MB, Wen Z. Development of an attached microalgal growth system for biofuel production. Applied Microbiology and Biotechnology, 2010, 85(3):525-534

[14] Shi J, Podola B, Melkonian M. Application of a prototype-scale twin-layer photobioreactor for effective $\mathrm{N}$ and $\mathrm{P}$ removal from different process stages of municipal 
wastewater by immobilized microalgae. Bioresource Technology, 2014, 154:260-266

[15] Rendon SM, Roldan GJ, Voroney RP. Effect of carbon dioxide concentration on the growth response of Chlorella vulgaris under four different LED illumination. International Journal of Biotechnology for Wellness Industries, 2013, 2(3):125-131

[16] Katarzyna L, Sai G, Singh OA. Non-enclosure methods for non-suspended microalgae cultivation: Literature review and research needs. Renewable and Sustainable Energy Reviews, 2015, 42:1418-1427

\section{How to cite this article:}

Sahib A A M, Lim J W, Lam M K, Uemura Y, Kutty S R M, Ramli A. Optimization of polyurethane foam cube in enhancing the attachment of microalgae biomass. J. Fundam. Appl. Sci., 2017, 9(6S), 642-650. 